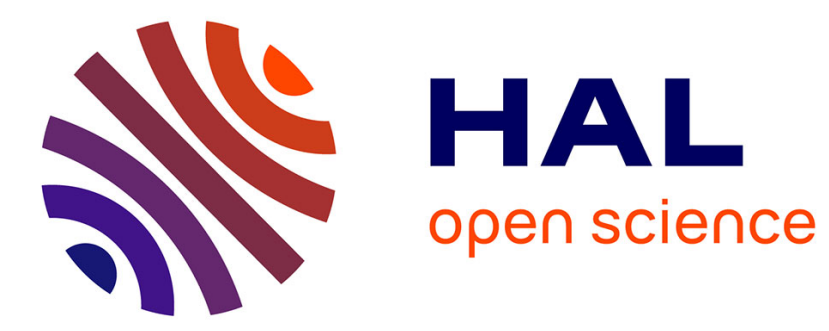

\title{
SPIN ASYMMETRIES IN PERTURBATIVE QCD AND BEYOND
}

G. Cocho, J. Rivera Rebolledo, M. Moreno

\section{To cite this version:}

G. Cocho, J. Rivera Rebolledo, M. Moreno. SPIN ASYMMETRIES IN PERTURBATIVE QCD AND BEYOND. Journal de Physique Colloques, 1985, 46 (C2), pp.C2-275-C2-280. 10.1051/jphyscol:1985231 . jpa-00224545

\section{HAL Id: jpa-00224545 https://hal.science/jpa-00224545}

Submitted on 1 Jan 1985

HAL is a multi-disciplinary open access archive for the deposit and dissemination of scientific research documents, whether they are published or not. The documents may come from teaching and research institutions in France or abroad, or from public or private research centers.
L'archive ouverte pluridisciplinaire HAL, est destinée au dépôt et à la diffusion de documents scientifiques de niveau recherche, publiés ou non, émanant des établissements d'enseignement et de recherche français ou étrangers, des laboratoires publics ou privés. 
JOURNAL DE PHYSIQUE

Colloque $\mathrm{C} 2$, supplément au $\mathrm{n}^{\circ} 2$, Tome 46, février 1985

page $\mathrm{C} 2-275$

\title{
SPIN ASYMMETRIES IN PERTURBATIVE QCD AND BEYOND ${ }^{+}$
}

\author{
G. Cocho, J.M. Rivera Rebolledo* and M. Moreno
}

Instituto de Física, Universidad Nacional Autónoma de México, México and

Departamento de Física, Centro de Investigación y de Estudios Avanzados del IPN, México

\begin{abstract}
Résumé : Nous prêsentons deux idées dans ce travaill. Premièrement nous montrons $\mathrm{qu}^{\prime} \mathrm{\prime n}$ traitement soigneux de l'amplitude de diffusion dure en QCD perturbatif n'est pas nécessairement en désaccord avec les résultats expérimentaux sur 1'asymétrie $A_{N N}$ dans la diffusion êlastique pp . La prëcédente borne $A_{N N} \leqslant 1 / 3$ est attribuée à l'approximation spectateur. Cependant, le schéma de QCD perturbatif ne peut pas $s^{\prime}$ accommoder de la polarisation $A \sim 0.5$ récemment mesurée. Nous proposons d'étendre le traitement perturbatif pour inclure des effets non perturbatifs qui pourraient expliquer ce nouvel effet.
\end{abstract}

Abstract : Two ideas are presented in this work. First, we show that a more carefu treatment of the hard scattering amplitude in perturbative QCD is not necessarily in disagreement with the experimental data for the proton-proton spin asymmetry $\mathrm{A}_{\mathrm{NN}}$. The previous bound of $\mathrm{A}_{\mathrm{NN}} \leqslant 1 / 3$ is attributed to the spectator approximation. However, the perturbative framework of QCD cannot be reconciled with the protonproton spin asymmetry $A \sim 0.5$ recently measured. We propose an extended perturbati treatment that includes non-perturbative effects that can explain this new data.

Polarized nucleon-nucleon scattering experiments have been producing extremely relevant data to test theoretical conceptions of the nucleon structure (1). In particular, perturbative Quantum Chromodynamics (2) (POCD) was believed to be in serious trouble in explaining the proton-proton $A_{N N}$ data at $\theta_{\mathrm{CM}}=90^{\circ}$ and

$\mathrm{P}_{\text {Lab }}=11.75 \mathrm{GeV} / \mathrm{C}$ (3). A more refined analysis here presented shows that this is not necessarily the case. However, as long as one sticks to a theoretical framework in which there are no single quark helicity flip amplitudes, one will not be able to describe a large value of the asymmetry A.

In this work we also show that, incorporating some non perturbative ideas suggested by lattice gauge theories, it is possible to extend POCD so that it will give helicity flip amplitudes.

1. Perturbative QCD Analysis

Among the large number of Feynman amplitudes that contribute to PQCD we have taken those on Fig. 1. The basic new ingredient is the inclusion of gluon lines in the formerly spectator quarks as required in PQCD. Some related diagrams have also been computed, for example, if in one or both of the would-be-spectator lines with one fermion propagator one interchanges the gluon interaction the diagram gives a vanishing contribution in the zero mass limit. These already shows that there is someting wrong with the spectator approximation.

\footnotetext{
* In sabbatical leave of Escuela Superior de Física y Mathemáticas IPN (México)

+Work supported in part by CONACYT-México
} 


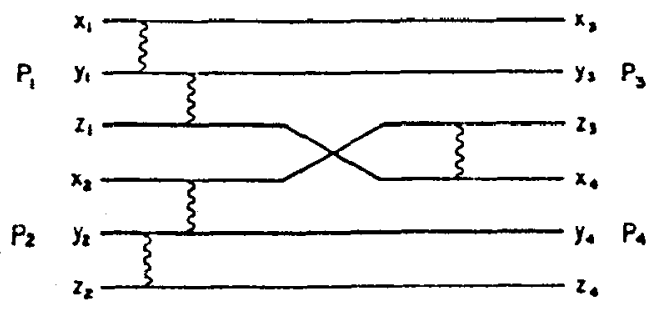

a.

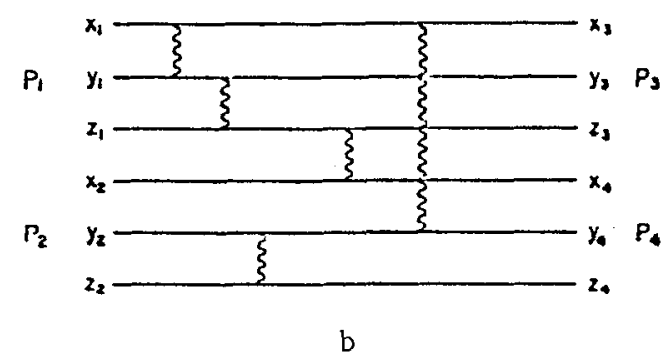

Fig. 1. Some of the PQCD diagrams that were computed.

A common feature of all the PQCD diagrams in the zero quark mass limit is that $\phi_{2}=\langle++|\hat{\phi}| \rightarrow\rangle$ and $\phi_{5}=\langle t+|\hat{\phi}|+\rightarrow\rangle$, due to helicity conservation. The diagrams in Fig. 1 give, with Pauli principle taken into account and symmetric $\mathrm{SU}_{\mathrm{H}}(6)$ wave functions,

$$
\begin{aligned}
& \phi_{1}^{\alpha}=g_{2}(t)+g_{2}(u), \\
& \phi_{3}^{\alpha}=-\frac{i 7}{26} \cos ^{2} \frac{\theta}{2} g_{2}(t), \\
& \phi_{4}^{\alpha}=\frac{17}{26} \sin ^{2} \frac{\theta}{2} g_{2}(u),
\end{aligned}
$$

and

$$
\begin{aligned}
& \phi_{1}^{b}=g_{3}(t)+g_{3}(u), \\
& \phi_{3}^{b}=\cos ^{2} \frac{\theta}{2} g_{3}(t), \\
& \phi_{3}^{b}=-\sin ^{2} \frac{\theta}{2} g_{3}(u),
\end{aligned}
$$

where

$$
g_{2}(t)=g_{2} \frac{s}{t^{4} \widetilde{s}} \quad \text { and } \quad g_{3}(t)=g_{3} \frac{s}{t^{5}}
$$

$\boldsymbol{s}$ is a linear function of $t$ and $u$ and $g_{2}$ and $g_{3}$ arise naturally from the calculation with opposite signs. If we now introduce a parameter to $f i x$ the relative weight between this two amplitudes one can fit the value of $A_{N N}$ at $90^{\circ}$. The resulting 
predicted angular distributions are given in Figs 2 and 3 . The value of $A$ within this framework is clearly zero because $\phi_{5}=0$.

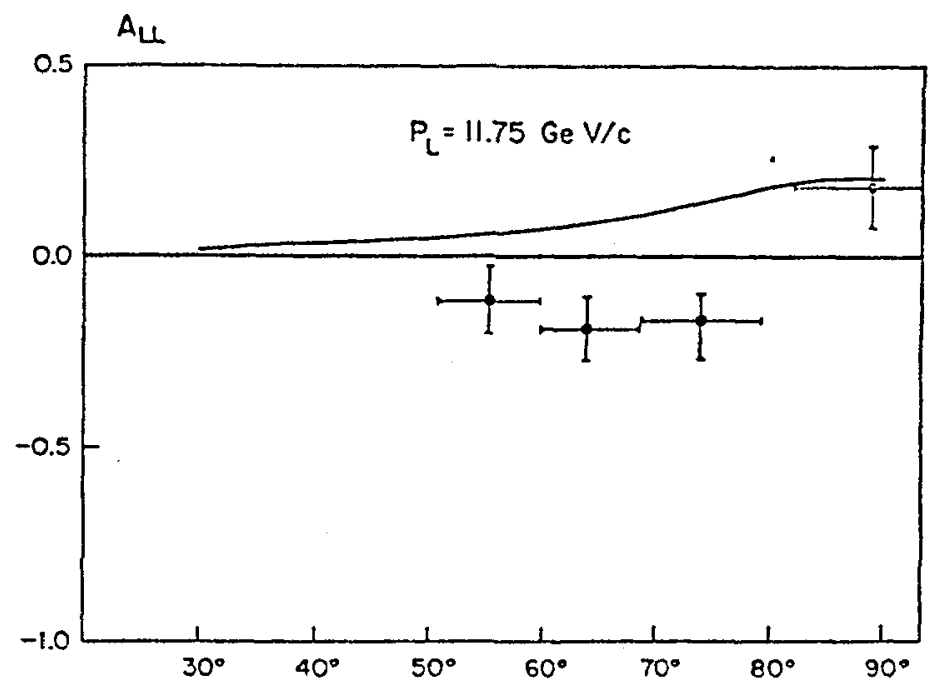

Fig.2. Predicted angular dependence of $A_{L L}$.

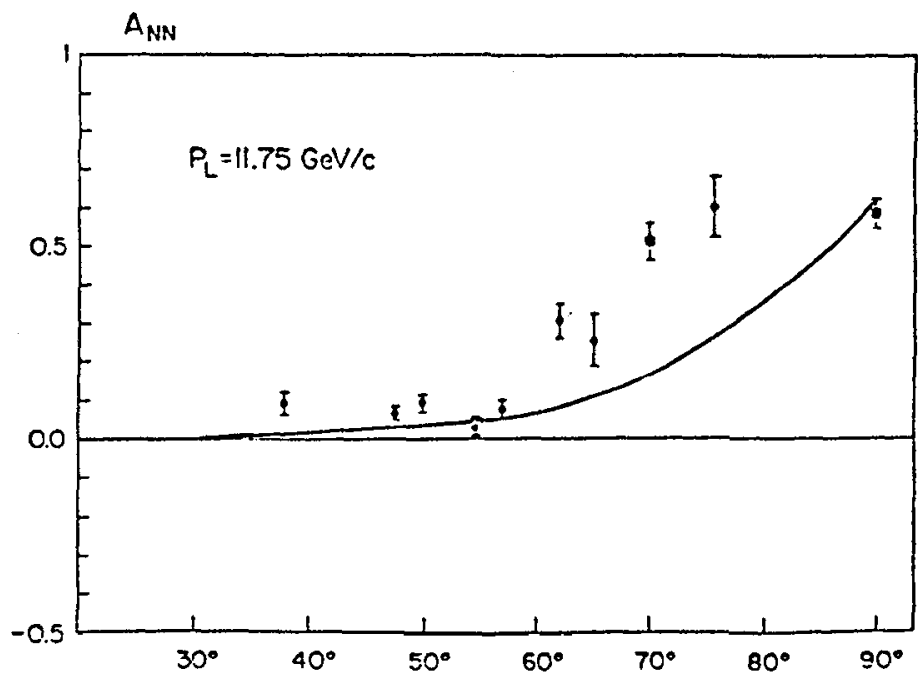

Fig. 3. Angular dependence of $A_{\mathrm{NN}}$. The $90^{\circ}$ point was fitted. 
The calculated angular distributions of $A_{N N}$ and $A_{L L}$ compare reasonably well with the data at $\mathrm{P}_{\mathrm{Lab}}=11.75$. Clearly, there $\mathrm{NN}$ is $\mathrm{LL}$ some structure still missing. Nontheless, this PQCD calculation has broken the $A_{N N} \leq 1 / 3$ bound of the spectator approximation. The large value of $\mathrm{A}_{\mathrm{NN}}$ was attributed in the past to spin correlations like diquarks. (4) What is remarkable of the diagrams computed is that they imply a strong correlation between the would be spectators. In particular, when the helicities of the "spectators" are parallel the diagram vanishes. Let us now point that an important unsolved problem is that of the stability of our computation. The amplitudes that have been studied have been selected through a simplicity cricerion. In order to improve the relaiability of PQCD one must include a grater number of diagrams. This leads to the development of symbolic manipulation programs (SMP) as the one recently developed by Neri and Farrar (5). We are developing a SMP based on a closed formula for the product of in Dirac matrices (6). This formula, when combined with a Caffo-Remiddi-like (7) algorithm for the computation of amplitudes, allows the use of general purpose SMP's. A typical diagram requires about 20 seconds of processor time of a Burroughs 7800 (about 1 minute of a VAX) in an unoptimized program written in Reduce (8).

Let us remark now that because helicity is conserved in the fermion lines, any PQCD calculation will predict $\phi_{5}=0$ and therefore will have problems with a large values of $A=0.5$ as the one recently reported (9). A possible dynamical mechanism that has the ingredients to explain a non null value of $A$ is therefore required.

\section{Extending PQCD with non-perturbative terms.}

It has been pointed out that the spontaneous breakdown of chiral symmetry is an a priori distinct phenomenon from confinement. In particular, kogut et a I. (10) have found that the relevant phase transitions occur at different temperatures in SU(2) and, to a smaller degree, in su(3). Therefore, those phenomena would differ dynamica$11 y$ also. In turn, Politzer (11) has proposed that these two temperatures (energies) can be interpreted as evidence that chiral breakdown occurs at a shorter distance and weaker coupling than the relevant for confinement in the zero temperature theory.

Motivated by these results, we have proposed (12) that these can be modeled by the presence of $\mathrm{q} \overrightarrow{\mathrm{q}}$, pion like, pseudoscalar states - chiralons - that hide the chiral symmetry even inside of the hadrons. The contributions of such states do not destroy the rather successful "counting rules" of PQCD or of the constitutent interchange mechanism (13). Furthermore, they give an additional contribution to $P Q C D$ that enhances $A_{N N}(12)$. The essential point is tha- for these contributions $\phi_{I}$ might be zero while $\phi_{2} \neq 0$.

However, chiralon exchange between quarks in the hadron produce $\phi_{5}=0$ because they flip the helicities of the two quarks that are involved. The way out of this problem is naturally provided by the mere existence of the chiralons because they imply a chiral anomaly.

The effective lagrangian of the extended POCD looks very much like the old time Ge11-Mann and Lévy (14) model and the chiral anomaly gives an adidional chiralongluon-gluon vertex; for color singlet chiralons this vertex is just :

$$
\text { if } \varepsilon_{\mu \nu \alpha \beta} \partial^{\mu} A_{a}^{\nu} \partial^{\alpha} A_{a}^{\beta}
$$

Actual evaluation of the diagram in Fig. 4 gives $\phi_{1}=\phi_{2}=\phi_{3}=\phi_{4}=0$ and $\phi_{5}=\alpha_{y}^{4} b_{x} f \sqrt{t u}\left[\frac{1}{t^{4}(s-3 u)}-\frac{1}{u^{4}(s-3 u)}\right]$, where $\alpha_{g}$ is the gluon quark coupling, and $b_{x}$ the chiralon quark coupling. 


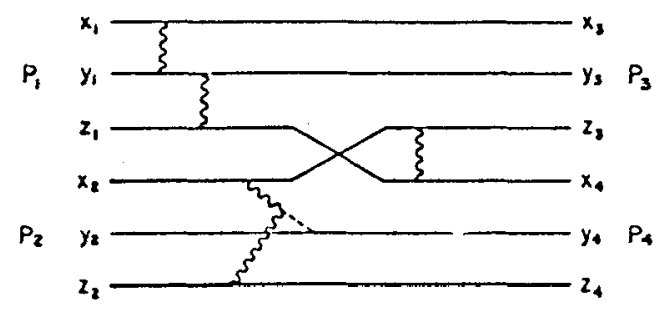

a

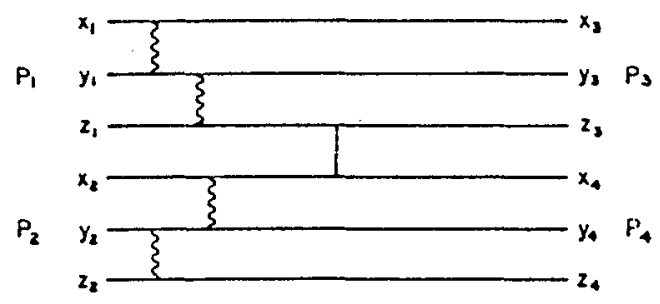

b

Fig.4. Non perturbative contributions to the amplitude. The upper diagram comes from the chiral anomaly. Dashed lines represent chiralons.

Thus we have shown that an extended PQCD is a promissing framework in which polarized nucleon-nucleon scattering data can be understood. This includes the new data with A significantly different from zero. Obviously, more work is needed to determine the actual size of the non-perturbative effects incorporated in this extended PQCD framework. Another, question to be addresed by future investigations is how persistent are this effects when the momentum transfer is increased.

\section{$\underline{\text { References }}$}

(1) CRABB D.G. et a1, Phys. Rev. Lett. 41 (1978) 1257.

For a recent review see, A.D. Krisch, Lecture at LAMPF II Workshop, Los Alamos, Sep. 1983. Preprint Univ, of Michigan UM-HE-83-18 and references therein. The new value of $A$ is reported in R.S. Raymond et al., Univ. of Michigan preprint UMHE-84-11 (1984)

(2) BRODSKY, S.J., and LEPAGE G., Phys. Rev. D24 (1980) 2157

(3) PREPARATA, G., in High-Energy Physics, with Polarized Beams and Polarized Targets, Proc. of the 1980 Int. Symp. at Lausanne, Ed. by C. Joseph and J. Soffer, Birkhäuser Verlag, Basel 1981. Experientia Supp. Vo1. 38, pag. 121

BRODSKY, S.J., ibid. pag. 169

MORENO, M. et al, ibid pag. 586

SZWED, J. , ibid. pag. 593

WOLTERS, G.F., ibid. pag. 593 
(4) AVILEZ, C. et al, Phys. Rev. D24 (1981) 634

(5) FARRAR, G. and NERI, F., Phys. Lett. 130B (1983) 109

(6) MORENO, M., "Closed Formula for the Product of $n$ Dirac Matrices", preprint CINVESTAV (Mexico) 1984

(7) CAFFO M. and REMI DDI E., Helv. Phys., Acta 55 (1982) 339

(8) HEARN, A.C., "Reduce 2, User's Manual", 2nd. Ed. Univ. of Utah preprint UCP-19, 1973

(9) RAYMOND, R.S., in ref. 1

(10) KOGUT, J. et al, Phys. Rev. Lett. 48 (1982) 1140; ibid 50 (1983) 393

(11) POLITZER H.D., Phys. Lett. 116B (1982) 171

(12) CoCHO, G. et al, preprint Inst. de Física, UNAM (Mexico), 1984

(13) BALNKENBECLER R., BRODSKY S.J. and GUNION J.F., Phys. Rev. D18 (1978) 900, and references therein.

(14) GELL-MANN M., and LEVY M., Nuovo Cimento 16 (1960) 705

LEVY M:, Nuovo Cimento $\underline{52}$ (1967) 23. 